\title{
A Conceptual Forecasting Analysis of International Trade Aspects Based on Globalization Impact Issues
}

\author{
Stamatis Kontsas, Stavros Kalogiannidis \\ Assistant Professor \\ Department of Business Administration University of Western Macedonia GREECE \\ Adjunct Lecturer \\ Department of Business Administration University of Western Macedonia GREECE
}

\begin{abstract}
Global GDP is really important for trade, since the larger the global economy, the more goods and services available for trade. Global GDP grew by around two-thirds in real terms between 2000 and 2020 - or $2.6 \%$ per year on average. 2020 saw some of the largest trade reductions and output volumes for both industrial production and goods trade since WWII. The year 2020 was marked by some of the largest reductions in trade and output volumes since WWII. The declines in both world industrial production and goods trade in the first half of 2020 were of similar depth to those at the trough of the Global Financial Crisis (GFC). In addition, trade and production impacts across specific goods, services and trade partners were highly varied.

Initial pandemic-era expectations for a double-digit decline in world merchandise trade in 2020 did not materialise. Global trade turned out to recover from the shock at an extraordinarily fast pace from around mid-2020.
\end{abstract}

Keywords: Trade, Globalization, Business cycle, Economic Impact, Growth

\section{Economic Background and Challenges}

The past two decades have been a volatile period in the world's economic history, punctuated by the 2008/9 financial crisis and the coronavirus pandemic (Chart 1). Excluding crisis years, growth averaged 3.5\% per year in the 2000s (2000-2007) and 2.9\% per year in the 2010s (2011-2019).

Chart 1: Global GDP growth in real terms

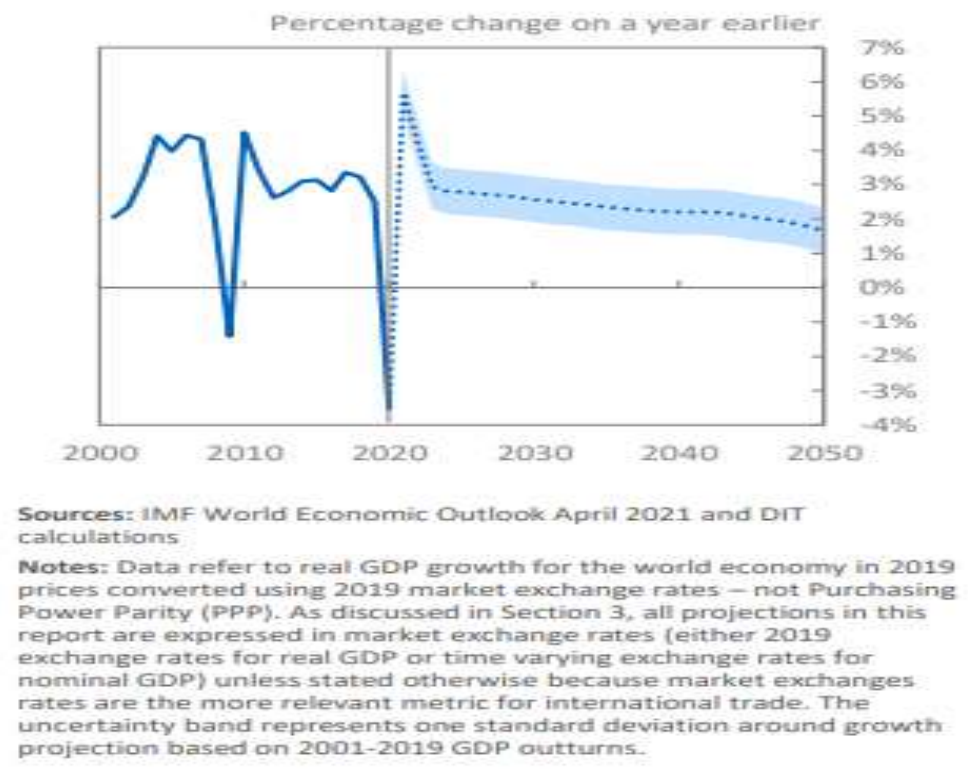

However, global trade recovered quickly from mid-2020. The impact across specific goods, services and trading partners was highly diverse. The World Trade Organization (WTO) estimates that the economic 
impact of the pandemic will vary across countries and regions, with a lasting effect on the world economy (WTO, 2020c).

This declining trend reflects a range of factors, including slower growth in the world's population; a slower pace of catch-up of emerging markets to the technological frontier; and weaker economic dynamism at the frontier itself - likely reflecting a slower pace of globalisation. Global GDP is expected to rebound in the near term from its pandemic-induced low. The 2021-2026 projections are conditioned on the IMF's April 2021 forecasts, which anticipate a rapid but partial recovery from the pandemic (IMF,2021). Over the coming decades, the underlying pace of global growth is expected to slow - averaging $2.3 \%$ per year in the $2030 \mathrm{~s}$ and $2.0 \%$ in the $2040 \mathrm{~s}$. These projections assume the factors that have caused global growth to slow in the first twenty years of this century will persist in the decades ahead. However, these projections are subject to wide bands of uncertainty both to downside risks (if further economic shocks materialise) and upside surprises (if technological progress accelerates). (Guerrieri et.al, 2020)

In dollar terms, the global economy is expected to be worth around $\$ 380$ tn by 2050, up from $\$ 87$ tn in 2019 (and \$84tn in 2020). This more than 300\% increase partly reflects real economic growth (which accounts for around a third of the overall increase), with the rest reflecting significant changes in prices and market exchange rates over the same period (Chart 2) (Guerrieri et.al., 2020)

\section{Chart 2: Global GDP in nominal terms}

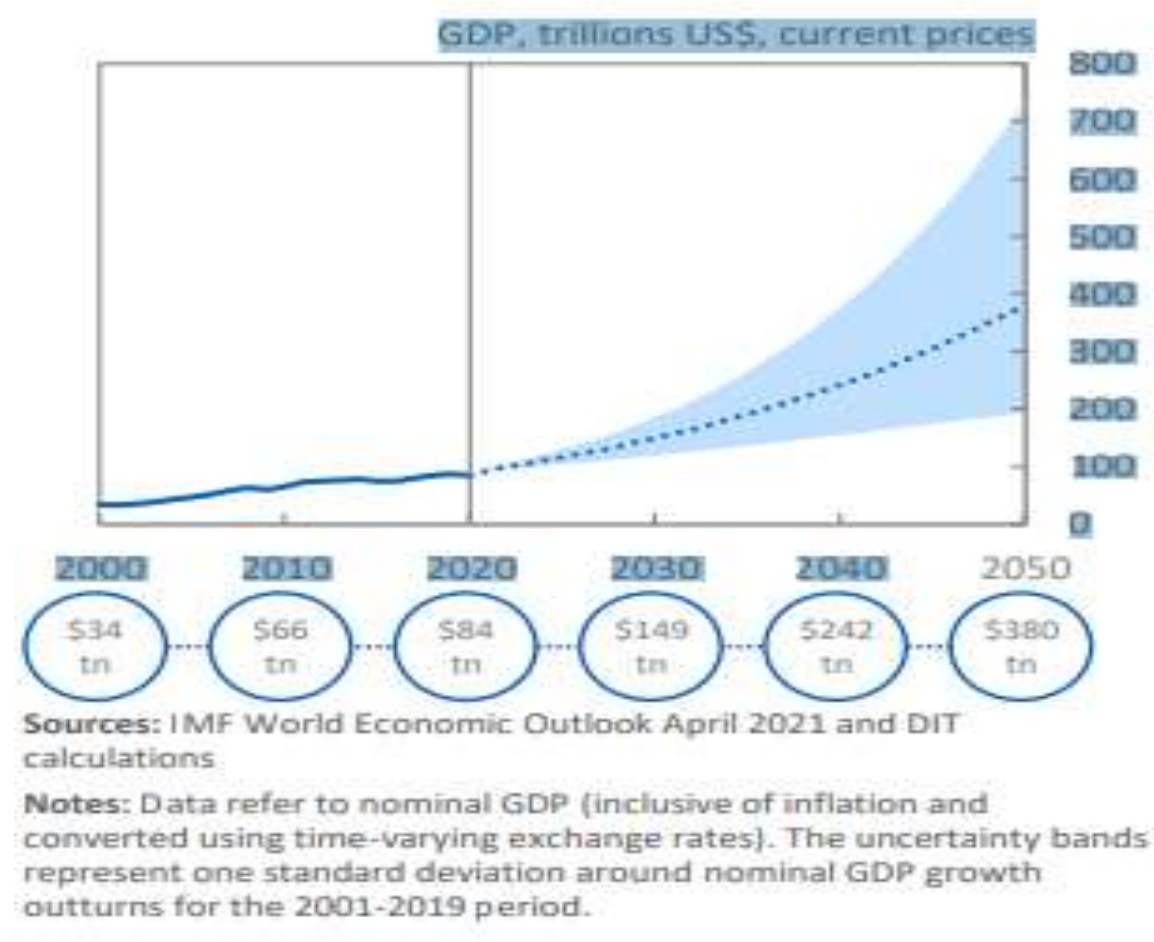

In dollar terms, global GDP is expected to increase by more than $300 \%$ over the next 30 years. The world's largest emerging economies will be a growing source of economic power. Economic power is expected to continue to shift from the G7 to the largest emerging economies. In the first two decades of this century, labour productivity growth (the main driver of higher living standards) was three times faster on average across the seven largest emerging economies than across the G7. As a result, the G7's share of global GDP fell from $65 \%$ in 2000 to $46 \%$ in 2020 , while the 'E7's' share rose from $11 \%$ to $28 \%$ (Chart 3).

\section{Chart 3 :G7 and 'E7' share of global GDP}




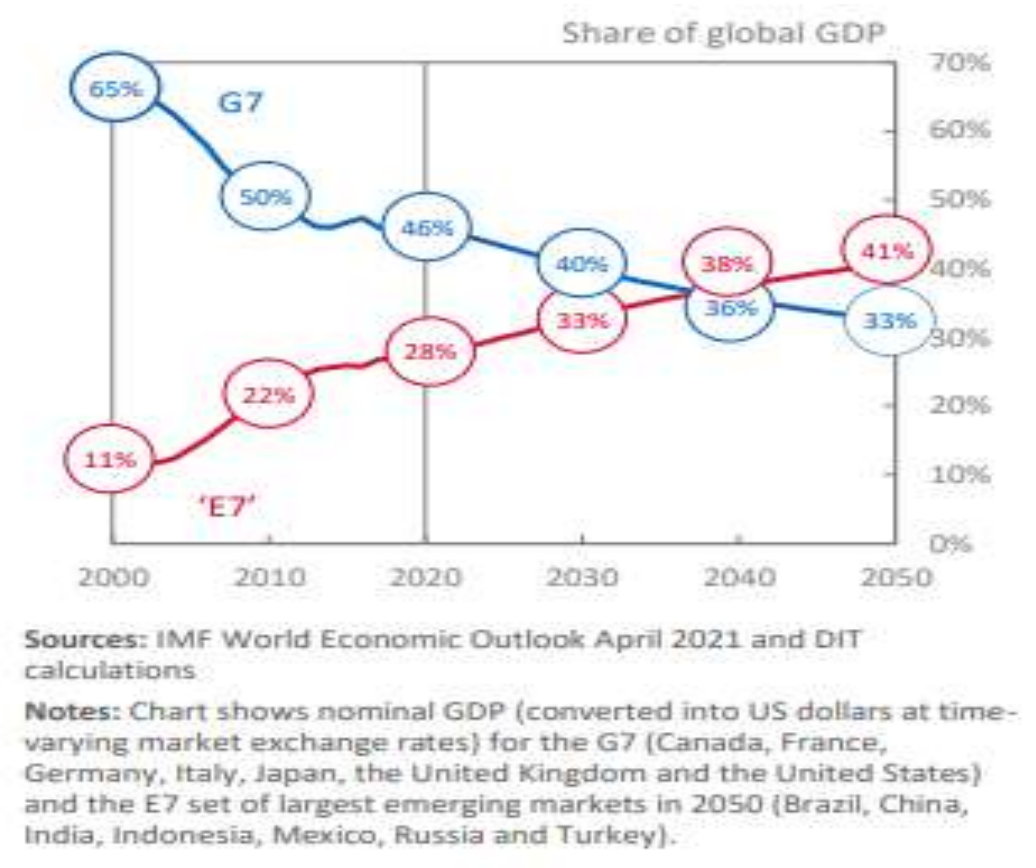

Over the next thirty years, labour productivity growth across the E7 is expected to grow at roughly twice the rate of the G7, with the E7 overtaking the G7 in economic size during the 2030s. This shift in economic power is likely to mean emerging economies will play a growing role in the global trading system. (Hevia and Neumeyer, 2020)

Global trade is estimated to remain below the pre-pandemic trade trend through 2021. The post-pandemic economic recovery is expected to be sluggish (IMF, 2020b), which may affect both domestic and foreign investment. The disruption of economic activity from the pandemic has the potential to be the most significant adverse macroeconomic shock in the past hundred years (Hevia and Neumeyer, 2020)

Ageing workforces will hold back growth, while urbanisation will continue to provide a tailwind.

The world's population is expected to rise from $7.8 \mathrm{bn}$ in 2020 to $8.5 \mathrm{bn}$ by 2030 . This $3 / 4$ billion rise is substantial, but it will be the smallest decade-long rise since the 1960s. Global population growth has been slowing for decades as populations in advanced economies have plateaued and birth rates in emerging markets have tapered. Slower population growth tends to result in slower economic growth (after 15-20 years) as there are fewer new workers, entrepreneurs and consumers to drive economic activity and demand. Global population growth is expected to continue to ease out to 2050 - when there should be 9.7 billion people on the planet or 2 billion more than today. (IMF,2021)

\section{Expectations of Global Economy Trends}

The urbanisation of the global economy is expected to continue, with an additional 800 million people living in cities by 2030. In 2020, 4.4 billion people lived in urban areas $-56 \%$ of the world's population. By 2030, this figure could reach 5.2 billion (60\%) and by 20506.7 billion (68\%). This assumes that the long-term urbanisation trend continues and that the COVID-induced flight from cities seen in some countries is temporary. Urbanisation is linked to higher productivity and higher living standards as cities offer economies of scale, agglomeration benefits and act as hubs for trade. So rising urbanisation rates are expected to continue to provide a tailwind to economic growth in the decades ahead. (WTO,2021)

The year 2020 was marked by some of the largest reductions in trade and output volumes since WWII. The declines in both world industrial production and goods trade in the first half of 2020 were of similar depth to those at the trough of the Global Financial Crisis (GFC). However, they materialised and disappeared more quickly, marking more of a $\mathrm{V}$ - shaped recovery in 2020. In addition, trade and production impacts across specific goods, services and trade partners were highly varied.

Initial pandemic-era expectations for a double-digit decline in world merchandise trade in 2020 did not materialise. Global trade turned out to recover from the shock at an extraordinarily fast pace from around mid-2020. This declining trend reflects a range of factors, including slower growth in the world's 
population; a slower pace of catch-up of emerging markets to the technological frontier; and weaker economic dynamism at the frontier itself - likely reflecting a slower pace of globalisation.

Global GDP is expected to rebound in the near term from its pandemic-induced low. The 2021-2026 projections in this report are conditioned on the IMF's April 2021 forecasts, which anticipate a rapid but partial recovery from the pandemic.

Over the coming decades, the underlying pace of global growth is expected to slow - averaging $2.3 \%$ per year in the $2030 \mathrm{~s}$ and $2.0 \%$ in the 2040s. These projections assume the factors that have caused global growth to slow in the first twenty years of this century will persist in the decades ahead. However,these projections are subject to wide bands of uncertainty both to downside risks (if further economic shocks materialise) and upside surprises (if technological progress accelerates). In dollar terms, the global economy is expected to be worth around \$380tn by 2050, up from \$87tn in 2019 (and \$84tn in 2020). This more than $300 \%$ increase partly reflects real economic growth (which accounts for around a third of the overall increase), with the rest reflecting significant changes in prices and market exchange rates over the same period.(IMF,2021)

\section{Global Trade Growth Aspects}

Global trade growth is closely related to GDP growth. The faster the world economy grows the faster trade tends to grow. However, trade is also more volatile than GDP. This is partly because most trade flows involve manufactured goods, which tend to vary more over the business cycle than the service sectors that dominate global GDP. The outlook for global trade is therefore even more uncertain than for GDP.

The IMF estimate world trade volumes fell by $8.5 \%$ in 2020 and will rebound by a similar amount in 2021. The IMF's April 2021 forecasts - on which the near-term projections in the Outlook are based assume trade will rebound from COVID-19 more slowly than global GDP.

During the 2030s and 2040s, global trade volumes are projected to grow in line with global GDP growth. There are many factors that could cause trade to grow faster or slower than GDP. These include: stability of the global trading system; political appetite for cross-border integration; business attitudes towards global value chains; and technological change. The projections in the Outlook take a neutral view of these factors and assume the status quo is maintained over the next 30 years. For example, in the case of the trading system, there is neither a further wave of globalisation - as happened before the global financial crisis - nor a turn inward. Different scenarios are clearly possible, so figures in the Outlook should be treated with wide bands of uncertainty. (WTO,2021)

By 2050, the value of global trade in dollar terms is expected to be worth around $\$ 100 t n$, up from \$24tn in 2019 .That 300\% increase is broadly in line with the rise in global GDP over the same period, with imports accounting for around a quarter of global GDP. Data quality and coverage mean that the Outlook focuses on gross trade.

After rebounding from the COVID-19 shock, global trade is expected to grow in line with global GDP.

By 2050, the four biggest regions will continue to dominate global import demand, but South Asia will also play a growing role. Europe is still likely to be the world's largest import market in 2050 but its share of global trade is expected to fall due to its slow pace of GDP growth. By contrast, rapid economic growth in the Indo Pacific - including in South Asia (led by India) - should see Asia's share of global trade rise and the axis of global trade shift further East (Ebsim et.al.,2020).

These trends will also affect the relative size of regional trade agreements over time. For example, the Comprehensive and Progressive Trans-Pacific Partnership's (CPTPP) import market size (based on its existing 11 members) could reach 54\% of the EU-27 market by 2050 - up from $48 \%$ in 2019.

Both the volume and (year-on-year) growth rates of world trade reached historical highs in May and June 2021. This is partially a reflection of the severe disruptions in trade in the first half of 2020 (leading to a low base), combined with the effect of releasing pent-up demand from 2020 and unwinding of the backlogs in international supply chains. Demand has resumed particularly in non-perishable goods, such as semiconductors, plastics, furniture, and bicycles, where production and delivery can be shifted across time. 
That said, in many countries, after a period of temporary de-confinement at the end of 2020, the beginning of 2021 was again marked by a wave of lockdowns and restrictions, which weighed on demand, supply and international trade. The recovery during the first half of 2021 continued to be asynchronous across countries and its pace continued to evolve over time. The growth in China's trade, exports in particular, was notably faster than that of other large economies in the second half of 2020 and early 2021. These factors complicate the assessment of the real overall strength of the trade recovery in 2021. (Ebsim et.al.,2020).

While it is still unknown which of the changes seen in 2020 will only be short-lived, some seem to suggest longer-term shifts or seem likely to result in long-term adjustments. Above all, the unprecedented heterogeneity of changes in trade flows across products, sources and destinations signifies high uncertainty and adjustment costs, and implies additional incentives for consumers, firms, and governments to adopt new — or to intensify existing — risk mitigation strategies.

The sectoral structure of global trade is currently dominated by goods sectors, unlike global GDP.

Trade in several types of goods and services plummeted, while that in others increased markedly. The product structure of merchandise trade changed significantly: trade in several products nosedived (e.g., fuels, aircrafts, cars, mechanical machinery, steel), while trade in some other products increased (e.g., protective equipment and pharmaceutical products, food, and 'home nesting' products such as domestic appliances and electronics).(WTO,2021)

Concluding Remarks

The analysis shows that the variation in trade impacts across the different product categories in 2020 was not only larger than during the GFC but also larger than in any other year in the past two decades.

Trade in several types of goods and services plummeted, while that in others increased markedly. The product structure of merchandise trade changed significantly: trade in several products nosedived (e.g., fuels, aircrafts, cars, mechanical machinery, steel), while trade in some other products increased (e.g., protective equipment and pharmaceutical products, food, and 'home nesting' products such as domestic appliances and electronics).

Chart 4: Percentage changes in trade of most popular trade products from 2008-2009.

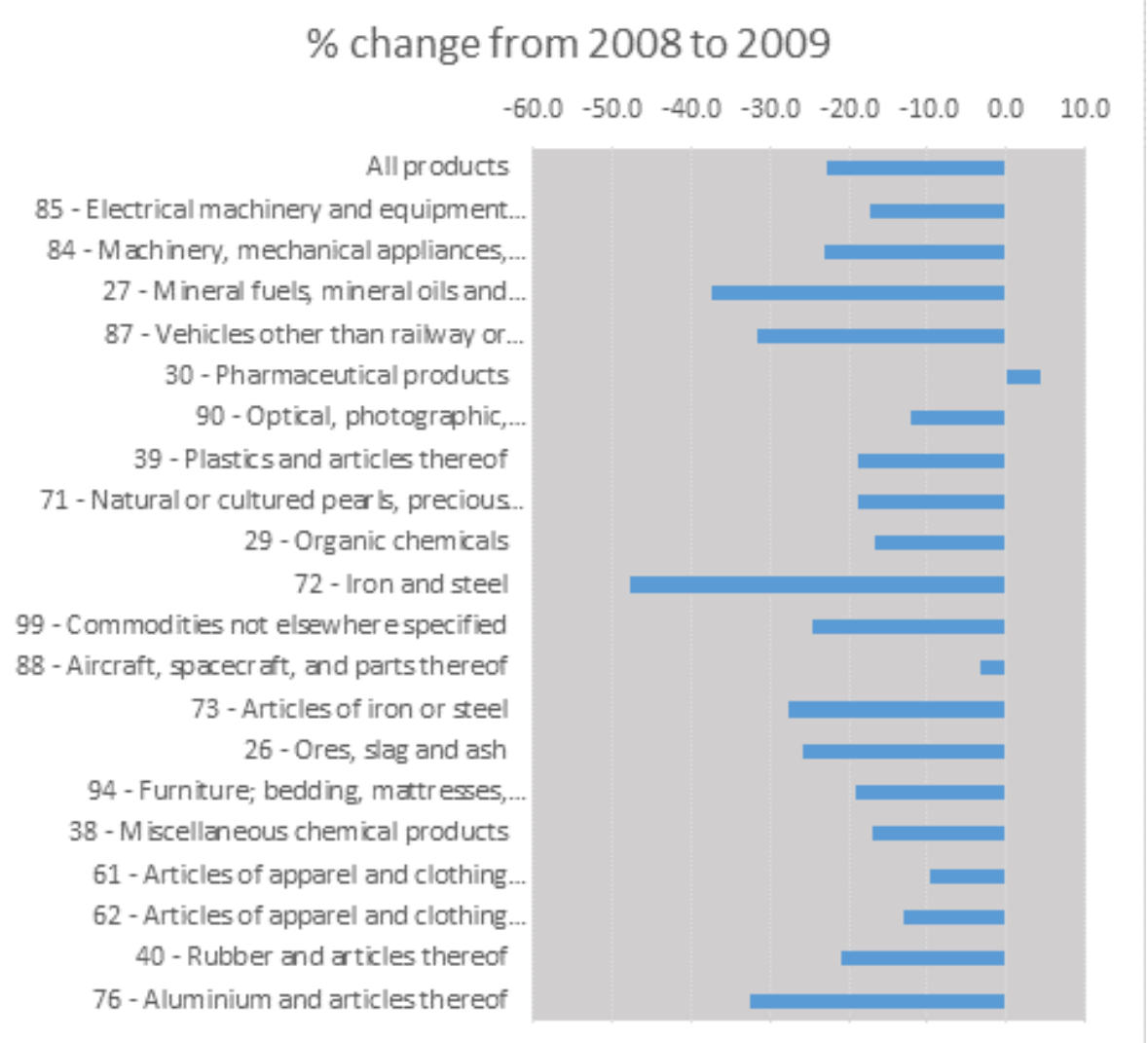

Source: World Economic Forum, 2021

Chart 5: Percentage changes in trade of most popular trade products from 2019-2020. 


\section{$\%$ change from 2019 to 2020}

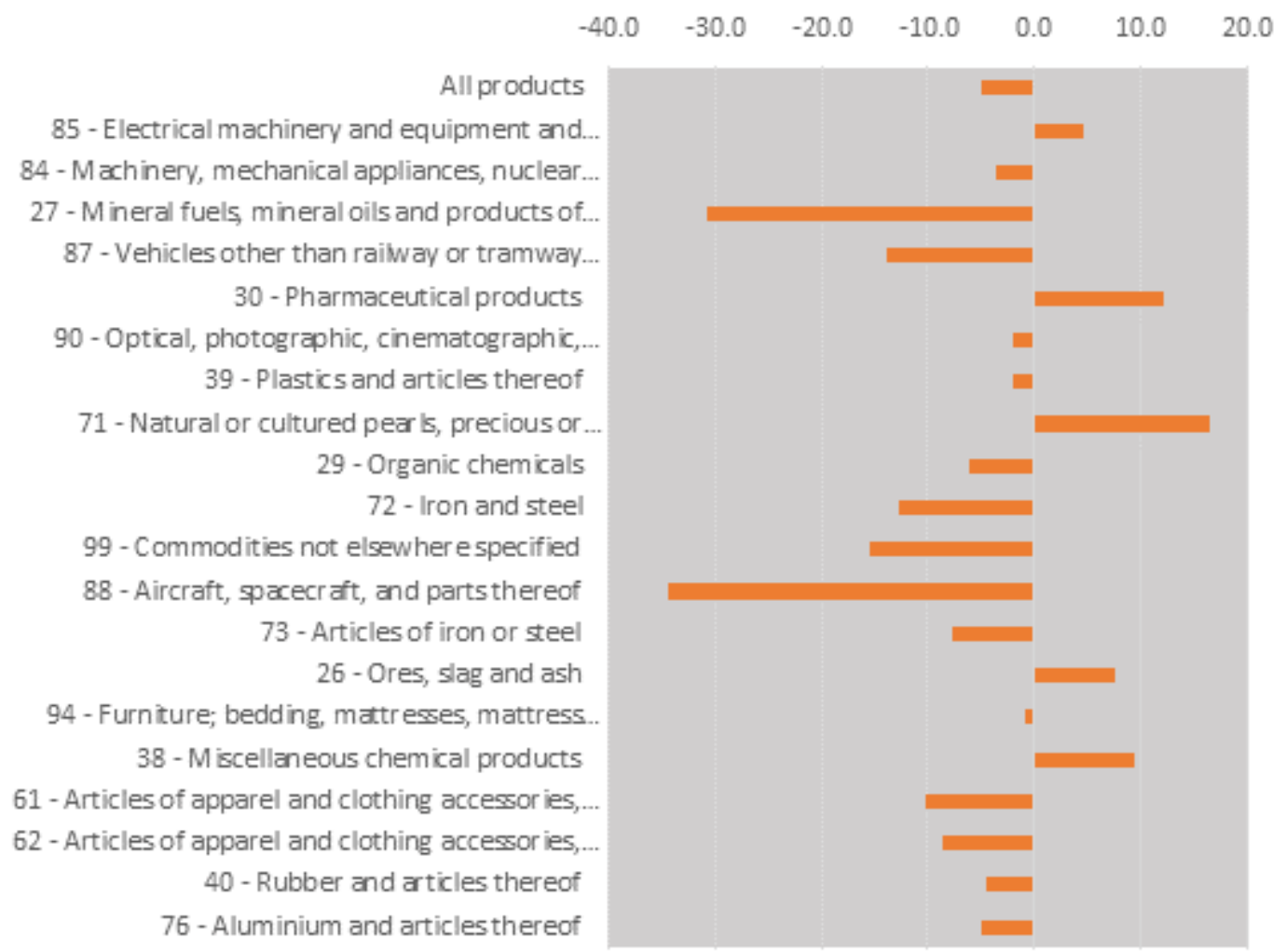

Source: World Economic Forum, 2021

The COVID-19 global pandemic continues to disrupt manufacturing and supply chains, with severe consequences for society, businesses, consumers and the global economy.(WTO,2021)

As the effects of coronavirus unfold, companies are asking what short-term actions they need to take to ensure business continuity and protect their employees. How should they be preparing for the rebound and increasing their manufacturing and supply systems' resilience?

The data so far suggests COVID-19 has had a much smaller impact on globalization than the 2008-09 global financial crisis, with rates of connectedness set to reach an all-time high in 2021.

Growth rates for international internet traffic may have doubled in 2020, with people connecting digitally rather than face-to-face, but have dropped as the recovery has gained pace. However, the value of world trade in services dropped by a fifth in 2020, which was almost entirely due to the collapse in travel and tourism, the report explains. In the fourth quarter of 2021, international travel is still more than $80 \%$ below its pre-pandemic level.(WTO,2021b).

\section{References}

1. Baldwin, R (2020), “COVID, remobilisation and the 'stringency possibility corridor': Creating wealth while protecting health", VoxEU.org, 10 April.

2. Dingel, J and B Neiman (2020), "How Many Jobs Can be Done at Home?", COVID Economics: Vetted and Real-Time Papers 1:16-24.

3. Ebsim, M, M Faria-e-Castro and J Kozlowski (2020), "Corporate Bond Spreads and the Effects of Unconventional Monetary Policy during the Pandemic", On The Economy Blog, Federal Reserve Bank of St Louis, 6 April.

4. Guerrieri V, G Lorenzoni, L Straub and I Werning (2020), "Macroeconomic Implications of COVID-19: Can Negative Supply Shocks Cause Demand Shortages?”, NBER Working Paper No. 26918.

5. IMF, World Economic Report(2021)

6. Hevia, C and P A Neumeyer (2020), "A Conceptual Framework for Analyzing the Economic Impact of COVID-19 and its Policy Implication”, UNDP LAC COVID-19 Policy Documents Series 1, 29 March. 
7. Reinsdorf, Marshall. (2020). "COVID-19 and the CPI: Is Inflation Working Paper 20/224, International Monetary Fund, Washington, DC.

8. OECD Economic Outlook(2021), A Balancing Act

9. OECD, Global Outlook, December 2021

10. Summers, Laurence H. (2021). "The Biden Stimulus Is Admirably Ambitious. But It Brings Some Big Risks, Too.” Opinion, Washington Post, February 4.

11. Powell, Jerome H. (2021). "Virtual Hearing-Oversight of the Treasury Department's and Federal Reserve's Pandemic Response."

12. Willems, Tim. (2020). "What Do Monetary Contractions Do? Evidence from Large Tightenings." Review of Economic Dynamics 38: 41-58.

13. World Economic Forum, 2021 